\title{
Cancer Rehabilitation Evaluation System for Research
}

National Cancer Institute

\section{Source}

National Cancer Institute. Cancer Rehabilitation Evaluation System for Research. NCI Thesaurus. Code C126278.

A self-reported, clinically relevant instrument designed to assess the rehabilitation needs and daily problems of patients with cancer. 